\title{
Chronic Kidney Disease of Unknown Origin: A Mysterious Epidemic
}

Gokul Paidi $^{1}$, Anuruddhika I. Iroshani Jayarathna ${ }^{2}$, Divya Bala Anthony Manisha R. Salibindla ${ }^{3}$, Jashvini Amirthalingam ${ }^{3}$, Katarzyna Karpinska-Leydier ${ }^{1}$, Khadija Alshowaikh ${ }^{4}$, Huseyin Ekin Ergin ${ }^{5}$

1. Internal Medicine, California Institute of Behavioral Neurosciences \& Psychology, Fairfield, USA 2. Neurology, California Institute of Behavioral Neurosciences \& Psychology, Fairfield, USA 3. General Medicine, California Institute of Behavioral Neurosciences \& Psychology, Fairfield, USA 4. Obstetrics and Gynecology, California Institute of Behavioral Neurosciences \& Psychology, Fairfield, USA 5. General Practice, California Institute of Behavioral Neurosciences \& Psychology, Fairfield, USA

Corresponding author: Gokul Paidi, gokulpaidi@gmail.com

\section{Abstract}

Amongst the many threats to health in our world, the most challenging ones are the ones with unknown causes. There is a mysterious epidemic of kidney disease called chronic kidney disease of unknown etiology $(\mathrm{CKDu})$ that is occurring in many parts of the world. Unrelated to known risk factors such as diabetes and hypertension, CKDu mostly affects the young and middle-aged, with slight preponderance in males. It mostly occurs in people living in rural areas, especially working in agricultural jobs. Worldwide, the number of people with chronic kidney disease, and those who need dialysis and renal replacement, is increasing every year as compared to other chronic conditions like diabetes and AIDS. It's not just alarming but a great challenge to healthcare systems across the world, especially in resource-poor countries. CKDu has become a silent killer for most patients. The occurrence of end-stage renal disease (ESRD) in CKDu can be catastrophic for individuals, especially in countries with limited medical facilities, causing a significant socio-economic burden. Even within these economically developing nations, people affected by CKDu usually are from the most vulnerable and underserved populations. As a definitive etiology has not been postulated for CKDu to date, this comprehensive review was undertaken to throw light on the poorly understood epidemiologic risk factors and the course of the disease.

Received 06/25/2021 Review began 07/29/2021 Review ended 08/03/2021 Published 08/12/2021

\section{() Copyright 2021}

Paidi et al. This is an open access article distributed under the terms of the Creative Commons Attribution License CC-BY 4.0., which permits unrestricted use, distribution, and reproduction in any medium, provided the original author and source are credited.
Categories: Internal Medicine, Nephrology, Epidemiology/Public Health

Keywords: chronic kidney disease (ckd), uddanam nephropathy, balkan endemic nephropathy, tondaimandalam nephropathy, unknown etiology, sri lanka nephropathy, mesoamerican nephropathy

\section{Introduction And Background}

Chronic kidney disease (CKD) could be a key determinant of unfavorable health consequences and is regarded as an independent risk factor for cardiovascular disease events. There has been a dramatic increase in the global burden of CKD over the last two decades [1]. Globally, the prevalence was estimated to be 147.6 million in 1990 and there was an increase to 275.9 million in 2016. Over the last two decades, there has been a doubling of crude mortality rate from approximately 0.59 million to 1.2 million [2]. The prevalence of CKD is disproportionately high in lower and middle-income economically developing countries as compared to high-income developed countries (>15\% higher) [3]. Although the primary cause of CKD varies across countries, hypertension and diabetes are the most common causes [4]. However, there has been a drastic increase in the incidence and prevalence of CKD of unknown etiology (CKDu) across different geographical regions, without any known risk factors [5-7].

Other terms utilized include 'CKD of nontraditional etiology', 'constant interstitial nephritis in agricultural communities', and 'kidney illness of unknown reason in horticultural workers'. Since it is commonly encountered in low-income, tropical/subtropical areas, rural and middle-aged men in agricultural and similar work requiring hard manual labor [8], CKDu has gained interest among researchers and clinicians in recent times.

Not surprisingly, there is a shortage of data on CKDu. However, data from the Indian CKD Registry revealed that $\mathrm{CKDu}$ is the second-most common underlying cause of CKD (16.0\%) after diabetic nephropathy (31.3\%) [9]. CKDu has a multifactorial etiology of different environmental and occupational exposures, such as heat stress, dehydration, agrochemicals (pesticides, herbicides, fertilizers), heavy metals (cadmium, lead, arsenic, etc.), water sources, and infections. It is life-threatening due to late recognition and rapid disease progression. Early screening of etiological risk factors for CKDu is essential to reduce the mortality and morbidity due to CKD. Various risk factors associated with CKDu are arsenic and cadmium in water, dehydration, extreme physical exertion, heat stress, agrochemical exposure, traditional nephrotoxic drugs like aristolochic acid, smoking, alcohol made with local traditional methods, infections, snake bites, and family history of CKD. 


\section{Cureus}

In Sri Lanka, CKDu was first reported in 1994 [6]. In 2017 and 2018, the Sri Lankan Society of Nephrology rectified the epidemiologic term of CKDu [10]. Despite this definition, there is a lack of consensus on criteria for diagnosis outside of kidney biopsy, with characteristic environmental and lifestyle exposures hypothesized to play an important role in disease identification and diagnosis [11]. In histopathology, the primary feature in CKDu is fibrosis in kidney tubules and interstitium with glomerular and vascular damage in different stages of evolution.

\section{Review}

\section{Epidemiology}

There had been evidence of various outbreaks of CKDu in the last two decades like the Balkan endemic nephropathy (BEN) in the Balkan States, Itai Itai nephropathy caused by cadmium-contaminated rice intake in Japan, aristolochic acid nephropathy (AAN) among users of herbal medicine in China, Taiwan, and other countries, Uddanam endemic nephropathy (UEN) in India, mesoamerican nephropathy (MeN) in Central America, and Sri Lanka nephropathy [12-15]. Recently, there have been claims to rename CKDu as chronic interstitial nephritis in agricultural communities (CINAC) [16,17]. All these share common features that interact with each other as shown in Figure 1.

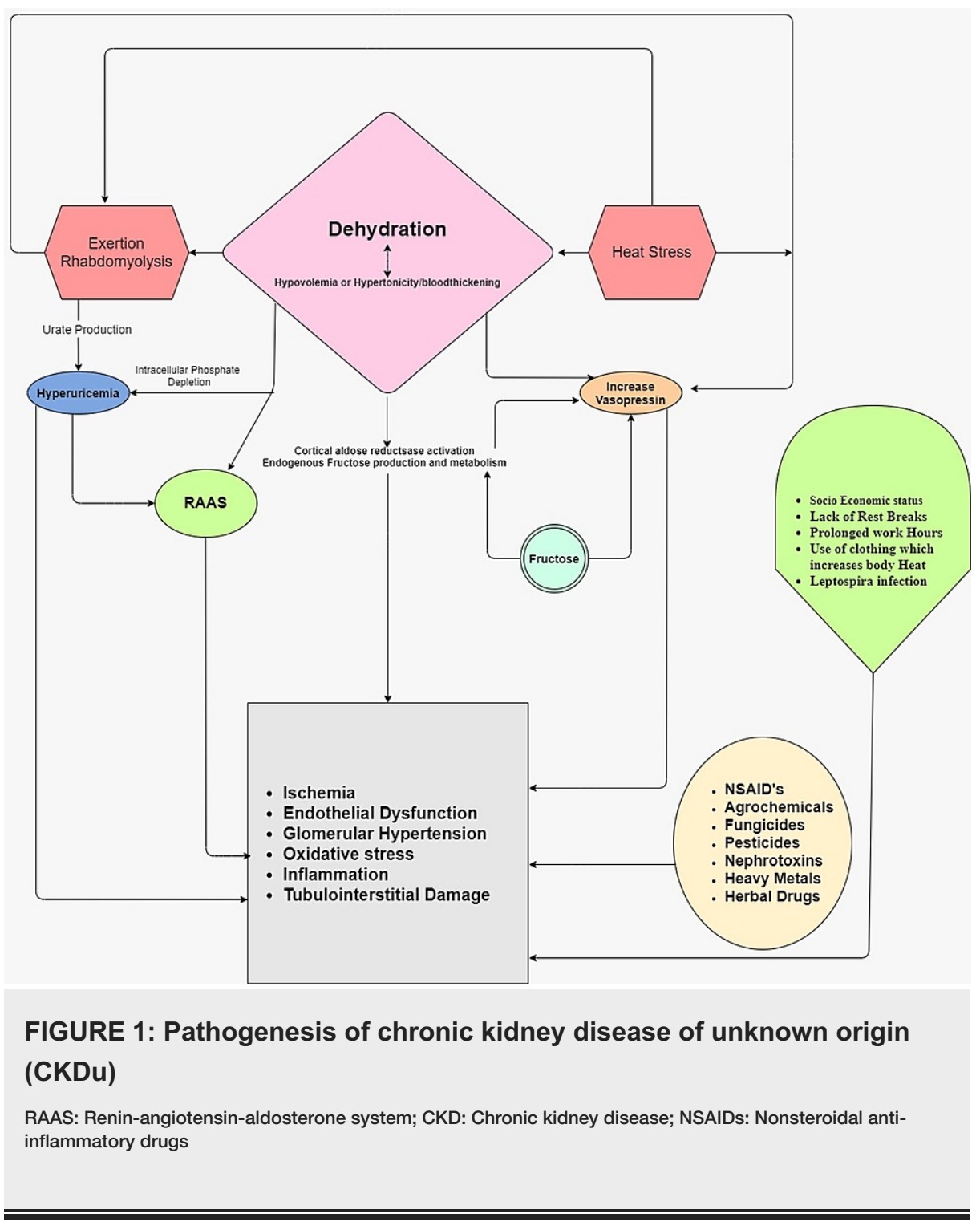

Balkan Endemic Nephropathy

First reported in 1956 in Bulgaria, BEN is a chronic tubule-interstitial disease that is slowly progressive and has a familial etiology. It is associated with the atypia of the urothelium, which sometimes can result in cancers of the renal pelvis and urethra [18]. It usually occurs in the fifth decade of life and renal failure usually is reported in the sixth and seventh decades of life. In 1957, patients in Yugoslavia (Serbia) presented with similar clinical signs and since then many cases have been reported. Most of the reported cases were 


\section{Cureus}

found in the Balkan peninsula and regions of southeast Europe. To be specific, it occurs among those living at the convergence of river Danube where there is high humidity and heavy rainfall [19]. The approximate prevalence of BEN in those regions ranges between 0.5-4.4\% [20]. However, the prevalence could be as high as $20 \%$ if the screening of high-risk populations is done since nearly all affected patients are farmers. It is noteworthy to mention that nearly $10 \%$ of patients in Bosnia with BEN present during the end-stage kidney failure (ESKD) stage [21]. The etiological factors, which were divided into exogenous and endogenous factors are shown in Table 1.

\begin{tabular}{|l|l|}
\hline Exogenous factors & Endogenous factors \\
\hline Lead intoxication & Genetic predisposition \\
Metals and metalloids & LCAT enzyme deficiency \\
Intoxication with Aristolochia clematitis & Genetic polymorphism \\
Ochratoxin A & Chromosomal aberrations \\
Pliocene lignite & Viral disease \\
Lecithin cholesterol acyltransferase and organic substances from coal & Immunological factors \\
& \\
\hline TABLE 1: Etiology of Balkan endemic nephropathy (BEN) & \\
\hline LCAT: Lecithin-cholesterol acyltransferase & \\
\hline
\end{tabular}

Literature has reported genetic predisposition to be the primary cause for BEN. There are strong arguments that environmental etiology also plays an important role in BEN such as chronic poisoning with aristolochic acids. The fact that it has been difficult to decipher the etiology of BEN for almost 50 years makes it valid to accept the argument that BEN may be caused due to the interplay of multiple etiologies. The clinical features of BEN usually range from non-specific symptoms to weakness and fatigue along with lumbar pain and discoloration of the palms and soles (copper-brown discoloration). At an advanced stage, it presents with anemia and loss of renal function leading to ESRD. Intermittent proteinuria, which is present in the earlier stage, becomes permanent in the uremic phase of the disease [22-24].

Itai-Itai Disease

Itai-Itai disease ('it hurts-it hurts' disease) was officially recognized in 1968 and was caused by activities related to industrialization. This chronic kidney disease mainly targets women living in rice farming regions near the polluted Jinzu river, which is high in cadmium and other heavy metals in Toyama, Japan. It has been acknowledged since the 1950s by the effort of residents and Dr.Hagino who was practicing general medicine in a clinic in the polluted river areas $[25,26]$. It's a kind of acquired Fanconi syndrome, portrayed by renal tubular dysfunction and osteomalacia, induced by chronic cadmium exposure through contaminated rice and drinking water $[27,28]$. These immunological adjustments of CKD might be seen in patients with Itai-Itai illness, causing infections, for example, pneumonia and gastrointestinal (GI) inflammation hence giving rise to high mortality [29].

Aristolochic Acid Nephropathy

A quickly progressive interstitial nephritis prompting ESRD and urothelial malignancy, AAN was first revealed in Belgium in a class of patients who had ingested weight loss pills containing powdered root concentrates of Chinese spices [30-32]. In most Asian countries, up to 70\% of people rely on conventional traditional medicines, which are made with different plant and animal products and there is a high risk of the disease in these countries due to the frequent use of aristolochic species [33,34]. AAN has predominantly raised serum creatinine, huge pallor, and histopathologic changes showing hypocellular interstitial infiltrates with serious fibrosis. Proceeding toward ESRD is fast, with most patients having a persistent kidney infection for under two years. Moreover, AAN is related to a $40-45 \%$ predominance of urothelial carcinomas [35]. The pathogenesis of AAN is shown in Figure 2. 


\section{Cureus}

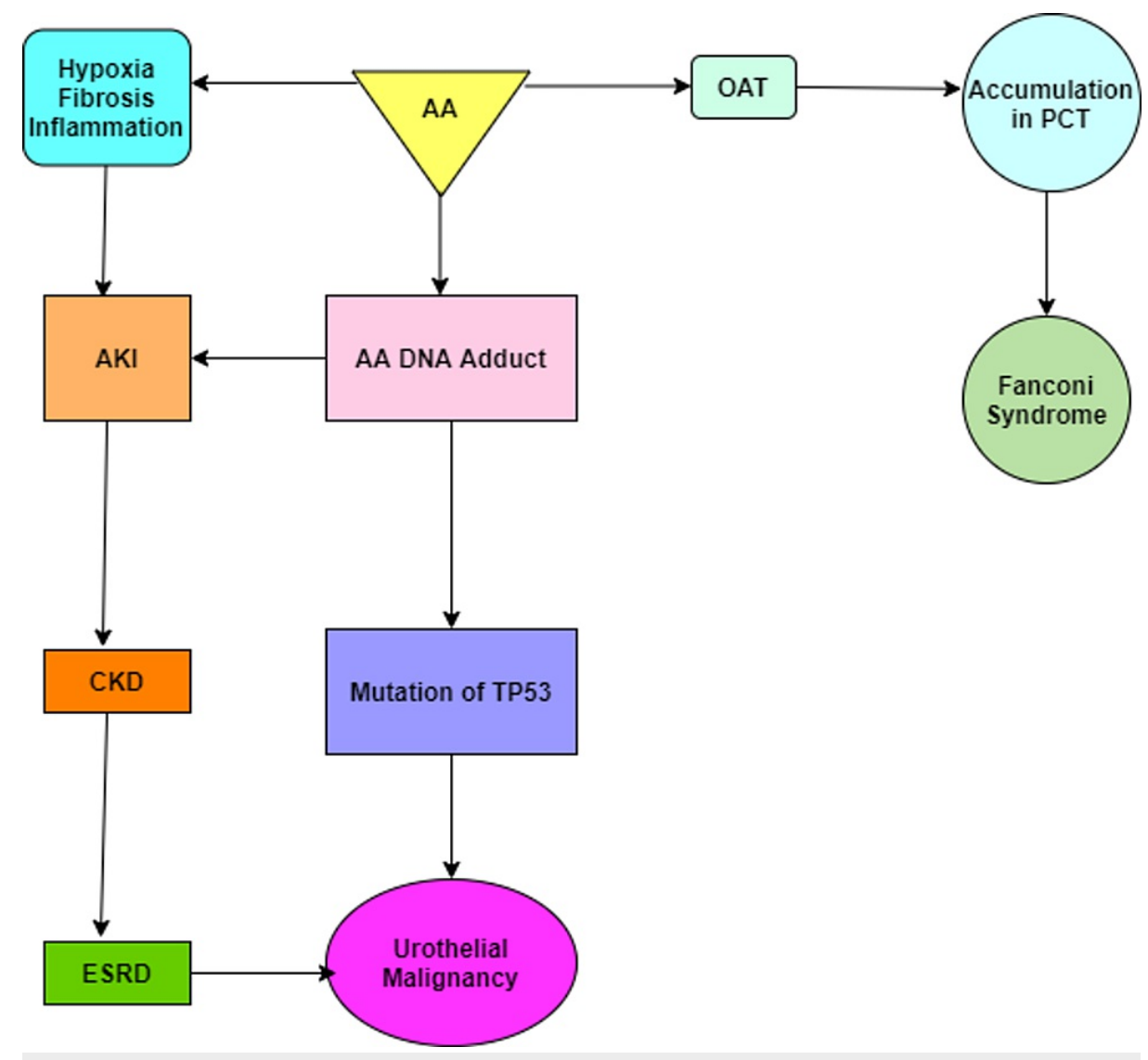

FIGURE 2: Pathogenesis of Aristolochic acid nephropathy (AAN)

AA: Aristolochic acid; AKI: Acute kidney injury; OAT: Organic anion transporter; CKD: Chronic kidney disease; PCT: Proximal convoluted tubule; ESRD: End-stage renal disease; TP53: Tumor protein P53

Aristolochic acid exposure is further associated with BEN; nevertheless, the disease course to kidney failure is significantly longer in AAN.

Mesoamerican Nephropathy

MeN or CKD of nontraditional reason [36] corresponds to CKD that presents in rural farm laborers, especially those working in sugarcane farms in Central America. [37,38]. The risk factors and etiology of MeN are unclear and debatable, and current evidence is limited. It is thought to be associated with poor living and occupational conditions with repeated episodes of heat stress, hypovolemia, loss of mineral dehydration, and prolonged working hours with lack of breaks use of clothing, which increases body heat [39-41]. Recently, nickel has shown a high association with the disease. Factors leading to MeN are shown in Figure 3. 


\section{Cureus}

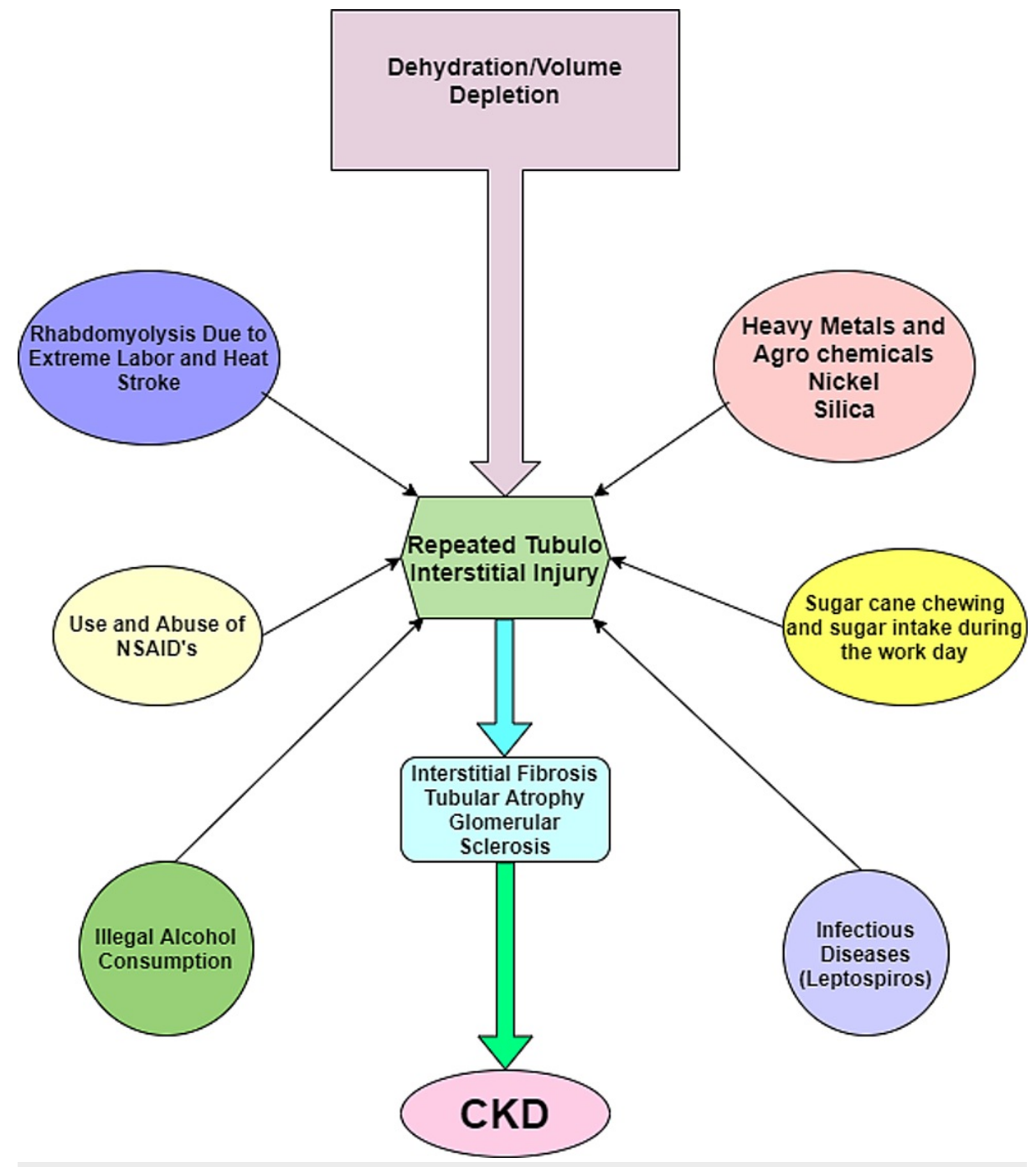

FIGURE 3: Pathogenesis of Mesoamerican Nephropathy (MeN)

CKD: Chronic kidney disease; NSAIDs: Non-steroidal anti-inflammatory drugs

Clinically, MeN manifests as a tubulointerstitial disease. Urinalysis shows low-range or no proteinuria, chemistry shows low serum potassium and sodium, and large degrees of uric acid, yet no hypertension. Histopathological features of the disease incorporate tubular atrophy, interstitial fibrosis, and global glomerulosclerosis.

Sri Lanka Nephropathy

First reported in the 1990s in Sri Lanka in the North Central Province, it is also called chronic agricultural nephropathy or CKD of multifactorial origin [42-43]. The reported prevalence of $8-21 \%$ is felt to be underreported due to the lack of sufficient data of epidemiologic studies on the disease [16]. The available literature has found that the disease is common among males and the rural population [44-46]. Although the similarities between endemics of CKDu in Central America and Sri Lanka are close, we lake proof in the matter of renal morphology. Sri Lankan nephropathy etiology has not yet been postulated but exposure to pesticides, fertilizers, heavy metals, hardness of water, and certain infections is suspected to play a role [4750]. Urine analysis has pointed toward heavy metal exposure as a possible cause but with limited validity $[45,51]$. The renal morphology of Sri Lanka nephropathy is frequently portrayed as tubulointerstitial nephritis/tubulointerstitial disease; however, huge glomerular lesions like total glomerulosclerosis, indications of glomerular ischemia, and inconsistent findings of focal glomerulosclerosis have additionally been accounted for $[44,45,52-54]$.

\section{Uddanam Endemic Nephropathy}

UEN was first reported in 1990 in the Uddanam region located in the Srikakulam district of Andhra Pradesh, 


\section{Cureus}

India [55]. As of 2015, around 34,000 people had kidney diseases in Uddanam [13,56]. The disease is known to disproportionately affect farmers and agricultural workers. Though it has been over thirty years since the first cases were reported, the cause of UEN is yet to be established. A study by Harvard University had reported that high levels of silica and heavy metals in water, prolonged dehydration, heat stress nephropathy, use of non-steroidal anti-inflammatory drugs (NSAIDs), gene mutations, and high use of pesticides are the probable cause of the condition. In histopathology, glomeruli were normal without any increase in cellularity, segmental lesions, or crescents. A diverse degree of ischemic changes and glomerular inactivity in addition to the atrophy of renal tubules and fibrosis of interstitium was seen. The inflammation was predominantly lymphomononuclear and around the atrophic tubules [57].

Tondaimandalam Nephropathy

A new and high prevalence of CKDu was noted in Tondaimandalam, in the southeastern coastal districts of Tamil Nadu and Puducherry, India, similar to the Uddanam region. The condition was commonly noted among the rice paddy, sugarcane, and peanut farming laborers engaged in herding animals and construction work. The clinical features include asymptomatic earlier stages, low-grade or absent proteinuria, and bilateral small kidneys. However, substantial data on the same is scarce since it is a new entity [58]. The epidemiological classification, etiology, and histopathological findings of the various CKDus are presented in Table 2 . 


\section{Cureus}

Chronic Kidney

Disease of

unknown origin

(CKDu)

\begin{tabular}{|ll} 
& Southeastern \\
& Europe \\
& (Balkans): \\
Balkan endemic & Serbia, Bosnia \\
nephropathy & and \\
(BEN) & Herzegovina, \\
& Croatia, \\
& Romania, and \\
& Bulgaria.
\end{tabular}

Itai-Itai disease Japan Farmers

Aristolochic acid Asian countries nephropathy mainly China

Coastal regions

of central

America

including

Mesoamerican Nicaragua and

nephropathy

El Salvador

mainly and to

some extent

Costa Rica and

Guatemala

$\begin{array}{ll}\text { Sri Lanka } & \text { North Central } \\ \text { nephropathy } & \text { Province of Sri } \\ \text { Lanka }\end{array}$

Agricultural workers

Agricultura workers

NSAIDs, heavy metals and agrochemical

Traditional medicine with Aristolochia species (Chinese herb)

Exogenous: Lead intoxication, Metals and metalloids, Intoxication with Aristolochia clematitis, Ochratoxin A and Pliocene lignite Endogenous: Genetic predisposition, LCAT enzyme deficiency, Genetic polymorphism, Chromosomal aberrations, Viral disease and Immunological factors Miscellaneous: Lecithin cholesterol acyltransferase and organic substances from coal

Chronic cadmium exposure through contaminated rice and drinking water exposure (inconsistent), rhabdomyolysis due to extreme labor and heat stroke, infectious diseases (leptospirosis)

Chronic tubulointerstitial disease with secondary glomerular and vascular damage; occasional global glomerulosclerosis from possible glomerular ischemia predominantly in the external part of the cortex, severe vascular changes, interstitial fibrosis, and scant inflammatory cell infiltrate. The renal pelvis and ureters revealed multiple urothelial papillomas and atypical urothelial hyperplasia

Tubulopathy of proximal tubules resulting in thinning of renal cortex and decrease in kidney weight

hypocellular interstitial infiltrate with severe fibrosis and urothelial carcinomas

Chronic tubulointerstitial fibrosis with nonspecific interstitial inflammation; rare glomerular collapse, and sclerosis with fibrous intimal thickening and arteriolar hyalinosis

Tubular atrophy and interstitial fibrosis mainly with secondary glomerular and vascular changes and rice farming inflammatory drugs (NSAIDs), gene mutations, and high use of pesticides

Not studied
Tondaimandalam Nephropathy
India (northern coastal districts of Tamil Nadu and Pondicherry)
Rice

paddy,

sugarcane, Not studied peanut farming

TABLE 2: Clinico-epidemiological features of major globally reported chronic kidney disease of unknown origin (CKDu)

LCAT: Lecithin-cholesterol acyltransferase

\section{Conclusions}

Diagnosis and treatment of $\mathrm{CKDu}$ is a relatively new phenomenon in areas where farming has been prevalent for centuries. This review was conducted mainly to find the similarities and differences between the $\mathrm{CKDu}$ in various geographical regions and different nations across the world. Although heat stress and dehydration are presently the largest research focus in Latin America, contamination of drinking water is a 
primary cause for CKDu in Asia with less emphasis on heat stress and dehydration. Apart from these variations, similarities in disease patterns include late presentation, prolonged non-symptomatic stage, non-glomerular proteinuria, and the absence of hypertension in the beginning stages of the disease leading to a decrease in glomerular filtration rate features that are typical of chronic tubulointerstitial disease. Moreover, they commonly affect rural farmers in tropical countries and are undetectable until the final stage when kidney failure is inevitable, and it becomes a burden for patients and their families, both financially and emotionally, to obtain dialysis. Renal replacement therapy is non-affordable and limited. Research studies to date that aim to pinpoint risk factors associated with CKDu are varied and limited in geographic scope. Without conducting studies that look at all possible etiologies across regions using a standardized approach, it is difficult to arrive at a standard management guideline and improved survival among these patients. Research should focus on developing specific biomarkers to detect the CKDu in the early stages of the disease so measures can be taken to halt the progression to ESRD. Region-specific research labs should be established in the affected areas across the world and should conduct more comprehensive research in collaboration with other regional labs by sharing information for public service and research purposes. Surveillance and standardized disease registries and monitoring systems for cases of CKD and CKDu are important. Strengthening national environmental toxicology and all epidemiologic networks by supporting open transparent information exchange is needed. Since CKDu is mostly occurring in resource-poor countries, the WHO should declare it a global epidemic and allocate more funding to these countries for research.

\section{Additional Information \\ Disclosures}

Conflicts of interest: In compliance with the ICMJE uniform disclosure form, all authors declare the following: Payment/services info: All authors have declared that no financial support was received from any organization for the submitted work. Financial relationships: All authors have declared that they have no financial relationships at present or within the previous three years with any organizations that might have an interest in the submitted work. Other relationships: All authors have declared that there are no other relationships or activities that could appear to have influenced the submitted work.

\section{References}

1. Xie Y, Bowe B, Mokdad AH, et al.: Analysis of the Global Burden of Disease study highlights the global, regional, and national trends of chronic kidney disease epidemiology from 1990 to 2016. Kidney Int. 2018, 94:567-81. 10.1016/j.kint.2018.04.011

2. Vos T, Abajobir AA, Abbafati C, et al.: Global, regional, and national incidence, prevalence, and years lived with disability for 328 diseases and injuries for 195 countries, 1990-2016: a systematic analysis for the Global Burden of Disease Study 2016. Lancet. 2017, 390:1211-59. 10.1016/S0140-6736(17)32154-2

3. Ene-Iordache B, Perico N, Bikbov B, et al.: Chronic kidney disease and cardiovascular risk in six regions of the world (ISN-KDDC): a cross-sectional study. Lancet Glob Health. 2016, 4:e307-19. 10.1016/S2214109X(16)00071-1

4. Couser WG, Remuzzi G, Mendis S, Tonelli M: The contribution of chronic kidney disease to the global burden of major noncommunicable diseases. Kidney Int. 2011, 80:1258-70. 10.1038/ki.2011.368

5. Gifford FJ, Gifford RM, Eddleston M, Dhaun N: Endemic nephropathy around the world. Kidney Int Rep. 2017, 2:282-92. 10.1016/j.ekir.2016.11.003

6. Jayasumana C, Paranagama P, Agampodi S, Wijewardane C, Gunatilake S, Siribaddana S: Drinking well water and occupational exposure to herbicides is associated with chronic kidney disease, in Padavi-Sripura, Sri Lanka. Environ Health. 2015, 14:6. 10.1186/1476-069X-14-6

7. Redmon JH, Elledge MF, Womack DS, et al.: Additional perspectives on chronic kidney disease of unknown aetiology (CKDu) in Sri Lanka--lessons learned from the WHO CKDu population prevalence study. BMC Nephrol. 2014, 15:125. 10.1186/1471-2369-15-125

8. Correa-Rotter R, Wesseling C, Johnson RJ: CKD of unknown origin in Central America: the case for a Mesoamerican nephropathy. Am J Kidney Dis. 2014, 63:506-20. 10.1053/j.ajkd.2013.10.062

9. Rajapurkar MM, John GT, Kirpalani AL, et al.: What do we know about chronic kidney disease in India: first report of the Indian CKD registry. BMC Nephrol. 2012, 13:10. 10.1186/1471-2369-13-10

10. Wijewickrama ES, Gunawardena N, Jayasinghe S, Herath C: CKD of unknown etiology (CKDu) in Sri Lanka: a multilevel clinical case definition for surveillance and epidemiological studies. Kidney Int Rep. 2019, 4:7815. 10.1016/j.ekir.2019.03.020

11. Anand S, Montez-Rath ME, Adasooriya D, et al.: Prospective biopsy-based study of CKD of unknown etiology in Sri Lanka. Clin J Am Soc Nephrol. 2019, 14:224-32. 10.2215/CJN.07430618

12. Weaver VM, Fadrowski JJ, Jaar BG: Global dimensions of chronic kidney disease of unknown etiology (CKDu): a modern era environmental and/or occupational nephropathy?. BMC Nephrol. 2015, 16:145. 10.1186/s12882-015-0105-6

13. Ganguli A: Uddanam nephropathy/regional nephropathy in India: preliminary findings and a plea for further research. Am J Kidney Dis. 2016, 68:344-8. 10.1053/j.ajkd.2016.04.012

14. Pavlović NM: Balkan endemic nephropathy-current status and future perspectives . Clin Kidney J. 2013, 6:257-65. 10.1093/ckj/sft049

15. Chandrajith R, Nanayakkara S, Itai K, et al.: Chronic kidney diseases of uncertain etiology (CKDue) in Sri Lanka: geographic distribution and environmental implications. Environ Geochem Health. 2011, 33:267-78. 10.1007/s10653-010-9339-1

16. Almaguer-López MA, Herrera-Valdés R, Orantes-Navarro CM : Chronic kidney disease of unknown etiology 
in agricultural communities. MEDICC Rev. 2014, 16:9-15. 10.37757/MR2014.V16.N2.12

17. Jayasumana C, Orantes C, Herrera R, et al.: Chronic interstitial nephritis in agricultural communities: a worldwide epidemic with social, occupational and environmental determinants. Nephrol Dial Transplant. 2017, 32:234-41. 10.1093/ndt/gfw346

18. Dimitrov PS, Simeonov VA, Stein AD: Balkan endemic nephropathy in Vratza, Bulgaria, 1964-1987: an epidemiologic analysis of population-based disease registers. Eur J Epidemiol. 2001, 17:847-53. 10.1023/a:1015653608151

19. Janković S, Bukvić D, Marinković J, Janković J, Marić I, Djukanović L: Trends in incidence and prevalence of Balkan endemic nephropathy in the three most affected villages in Serbia over a 36-year period. Ren Fail. 2013, 35:509-13. 10.3109/0886022X.2013.773916

20. Ceović S, Hrabar A, Sarić M: Epidemiology of Balkan endemic nephropathy. Food Chem Toxicol. 1992, 30:183-8. 10.1016/0278-6915(92)90031-f

21. Djukanović L, Radović M, Baković J, et al.: Epidemiology of end-stage renal disease and current status of hemodialysis in Yugoslavia. Int J Artif Organs. 2002, 25:852-9. 10.1177/039139880202500907

22. Djukanović L, Marić I, Marinković J, Ignjatović S, Bukvić D: Evaluation of criteria for the diagnosis of Balkan endemic nephropathy. Ren Fail. 2007, 29:607-14. 10.1080/08860220701392231

23. Cukuranovic R, Jovanovic I, Miljkovic S, Stefanovic N, Vlajkovic S, Prokopovic M, Stefanovic V: Hemodialysis treatment in patients with Balkan endemic nephropathy: an epidemiological study . Ren Fail. 2007, 29:805-10. 10.1080/08860220701573475

24. Dimitrov P, Tsolova S, Georgieva R, Bozhilova D, Simeonov V, Bonev A, Karmaus W: Clinical markers in adult offspring of families with and without Balkan Endemic Nephropathy. Kidney Int. 2006, 69:723-9. 10.1038/sj.ki.5000120

25. Friberg L, Kjellström T: Cadmium. Disorders of mineral metabolisms: trace minerals. Bronner F, Coburn JW (ed): Academic Publishers, Cambridge, US; 1981. 317-52. 10.1016/B978-0-12-135301-8.50015-7

26. Nishijo M, Nakagawa H, Suwazono Y, Nogawa K, Kido T: Causes of death in patients with Itai-itai disease suffering from severe chronic cadmium poisoning: a nested case-control analysis of a follow-up study in Japan. BMJ Open. 2017, 7 :e015694. 10.1136/bmjopen-2016-015694

27. Aoshima K: Itai-itai disease: renal tubular osteomalacia induced by environmental exposure to cadmiumhistorical review and perspectives. Soil Sci Plant Nutr. 2016, 62:319-26. 10.1080/00380768.2016.1159116

28. Aoshima K: Itai-itai disease: cadmium-induced renal tubular osteomalacia [Article in Japanese]. Nihon Eiseigaku Zasshi. 2012, 67:455-63. 10.1265/jih.67.455

29. Kurts C, Panzer U, Anders HJ, Rees AJ: The immune system and kidney disease: basic concepts and clinical implications. Nat Rev Immunol. 2013, 13:738-53. 10.1038/nri3523

30. Vanherweghem JL, Tielemans C, Abramowicz D, et al.: Rapidly progressive interstitial renal fibrosis in young women: association with slimming regimen including Chinese herbs. Lancet. 1993, 341:387-91. 10.1016/0140-6736(93)92984-2

31. Depierreux M, Van Damme B, Vanden Houte K, Vanherweghem JL: Pathologic aspects of a newly described nephropathy related to the prolonged use of Chinese herbs. Am J Kidney Dis. 1994, 24:172-80. 10.1016/s0272-6386(12)80178-8

32. Vanhaelen M, Vanhaelen-Fastre R, But P, Vanherweghem JL: Identification of aristolochic acid in Chinese herbs. Lancet. 1994, 15:174. 10.1016/s0140-6736(94)90964-4

33. Hsieh SC, Lin IH, Tseng WL, Lee CH, Wang ID: Prescription profile of potentially aristolochic acid containing Chinese herbal products: an analysis of National Health Insurance data in Taiwan between 1997 and 2003. Chin Med. 2008, 3:13. 10.1186/1749-8546-3-13

34. Lai MN, Lai JN, Chen PC, Tseng WL, Chen YY, Hwang JS, Wang JD: Increased risks of chronic kidney disease associated with prescribed Chinese herbal products suspected to contain aristolochic acid. Nephrology (Carlton). 2009, 14:227-34. 10.1111/j.1440-1797.2008.01061.x

35. Reginster F, Jadoul M, van Ypersele de Strihou C: Chinese herbs nephropathy presentation, natural history and fate after transplantation. Nephrol Dial Transplant. 1997, 12:81-6. 10.1093/ndt/12.1.81

36. Lozier M, Turcios-Ruiz RM, Noonan G, Ordunez P: Chronic kidney disease of nontraditional etiology in Central America: a provisional epidemiologic case definition for surveillance and epidemiologic studies. Rev Panam Salud Publica. 2016, 40:294-300.

37. Wesseling C, Crowe J, Hogstedt C, Jakobsson K, Lucas R, Wegman DH: Resolving the enigma of the mesoamerican nephropathy: a research workshop summary. Am J Kidney Dis. 2014, 63:396-404. 10.1053/j.ajkd.2013.08.014

38. Martín-Cleary C, Ortiz A: CKD hotspots around the world: where, why and what the lessons are. A CKJ review series. Clin Kidney J. 2014, 7:519-23. 10.1093/ckj/sfu118

39. Nerbass FB, Pecoits-Filho R, Clark WF, Sontrop JM, McIntyre CW, Moist L: Occupational heat stress and kidney health: from farms to factories. Kidney Int Rep. 2017, 2:998-1008. 10.1016/j.ekir.2017.08.012

40. Madero M, García-Arroyo FE, Sánchez-Lozada LG: Pathophysiologic insight into MesoAmerican nephropathy. Curr Opin Nephrol Hypertens. 2017, 26:296-302. 10.1097/MNH.0000000000000331

41. Johnson RJ, Wesseling C, Newman LS: Chronic kidney disease of unknown cause in agricultural communities. N Engl J Med. 2019, 380:1843-52. 10.1056/NEJMra1813869

42. Ranasinghe AV, Kumara GW, Karunarathna RH, et al.: The incidence, prevalence and trends of chronic kidney disease and chronic kidney disease of uncertain aetiology (CKDu) in the North Central Province of Sri Lanka: an analysis of 30,566 patients. BMC Nephrol. 2019, 20:338. 10.1186/s12882-019-1501-0

43. Wimalawansa SJ: Escalating chronic kidney diseases of multi-factorial origin in Sri Lanka: causes, solutions, and recommendations. Environ Health Prev Med. 2014, 19:375-94. 10.1007/s12199-014-0395-5

44. Athuraliya TN, Abeysekera DT, Amerasinghe PH, Kumarasiri PV, Dissanayake V: Prevalence of chronic kidney disease in two tertiary care hospitals: high proportion of cases with uncertain aetiology. Ceylon Med J. 2009, 54:23-5. 10.4038/cmj.v54i1.471

45. Jayatilake N, Mendis S, Maheepala P, Mehta FR: Chronic kidney disease of uncertain aetiology: prevalence and causative factors in a developing country. BMC Nephrol. 2013, 14:180. 10.1186/1471-2369-14-180

46. Wijetunge S, Ratnatunga NV, Abeysekera DT, Wazil AW, Selvarajah M, Ratnatunga CN: Retrospective 
analysis of renal histology in asymptomatic patients with probable chronic kidney disease of unknown aetiology in Sri Lanka. Ceylon Med J. 2013, 58:142-7. 10.4038/cmj.v58i4.6304

47. Wanigasuriya K: Update on uncertain etiology of chronic kidney disease in Sri Lanka's north-central dry zone. MEDICC Rev. 2014, 16:61-5. 10.37757/MR2014.V16.N2.10

48. Jayasumana C, Gunatilake S, Siribaddana S: Simultaneous exposure to multiple heavy metals and glyphosate may contribute to Sri Lankan agricultural nephropathy. BMC Nephrol. 2015, 16:103. 10.1186/s12882-0150109-2

49. Bandara JM, Senevirathna DM, Dasanayake DM, Herath V, Bandara JM, Abeysekara T, Rajapaksha KH: Chronic renal failure among farm families in cascade irrigation systems in Sri Lanka associated with elevated dietary cadmium levels in rice and freshwater fish (Tilapia). Environ Geochem Health. 2008, 30:465-78. 10.1007/s10653-007-9129-6

50. Gamage CD, Yoshimatsu K, Sarathkumara YD, Kulendiran T, Nanayakkara N, Arikawa J: Serological evidence of hantavirus infection in Girandurukotte, an area endemic for chronic kidney disease of unknown aetiology (CKDu) in Sri Lanka. Int J Infect Dis. 2017, 57:77-8. 10.1016/j.ijid.2017.02.004

51. Bandara JM, Wijewardena HV, Liyanege J, Upul MA, Bandara JM: Chronic renal failure in Sri Lanka caused by elevated dietary cadmium: Trojan horse of the green revolution. Toxicol Lett. 2010, 198:33-9. 10.1016/j.toxlet.2010.04.016

52. Nanayakkara S, Komiya T, Ratnatunga N, et al.: Tubulointerstitial damage as the major pathological lesion in endemic chronic kidney disease among farmers in North Central Province of Sri Lanka. Environ Health Prev Med. 2012, 17:213-21. 10.1007/s12199-011-0243-9

53. Badurdeen Z, Nanayakkara N, Ratnatunga NV, et al.: Chronic kidney disease of uncertain etiology in Sri Lanka is a possible sequel of interstitial nephritis!. Clin Nephrol. 2016, 86:106-9. 10.5414/CNP86S115

54. Selvarajah M, Weeratunga P, Sivayoganthan S, Rathnatunga N, Rajapakse S: Clinicopathological correlates of chronic kidney disease of unknown etiology in Sri Lanka. Indian J Nephrol. 2016, 26:357-63. 10.4103/0971-4065.167280

55. Reddy DV, Gunasekar A: Chronic kidney disease in two coastal districts of Andhra Pradesh, India: role of drinking water. Environ Geochem Health. 2013, 35:439-54. 10.1007/s10653-012-9506-7

56. Abraham G, Varughese S, Thandavan T, et al.: Chronic kidney disease hotspots in developing countries in South Asia. Clin Kidney J. 2016, 9:135-41. 10.1093/ckj/sfv109

57. Gowrishankar S, Koshy P, Mathew M, Gopalakrishnan N, Kumar VS, Abraham G: Pathology of Uddanam endemic nephropathy. Indian J Nephrol. 2020, 30:253-5. 10.4103/ijn.IJN_363_18

58. Parameswaran S, Rinu PK, Kar SS, et al.: A newly recognized endemic region of CKD of undetermined etiology (CKDu) in South India-"Tondaimandalam nephropathy". Kidney Int Rep. 2020, 5:2066-73. 10.1016/j.ekir.2020.08.032 